\title{
A study of Savitzky-Golay filters for derivatives in primary shock calibration
}

\author{
Hideaki Nozato ${ }^{1}$, Thomas Bruns ${ }^{2}$, Henrik Volkers ${ }^{2}$, Akihiro Oota ${ }^{1}$ \\ ${ }^{1}$ National Metrology Institute of Japan, Umezono 1-1-1, 3058563 Tsukuba Ibaraki, Japan \\ 2 Physikalisch-Technische Bundesanstalt, Bundesallee 100, 38116 Braunschweig, Germany
}

\begin{abstract}
This manuscript reports the result of an investigation into two types of digital filters for numerical differentiation of the displacement signal in the case of primary shock calibration of accelerometers. The first is a difference method with a $4^{\text {th }}$-order Butterworth lowpass $\left(4^{\text {th }} \mathrm{BW}\right)$ filter; the other is a Savitzky-Golay $(\mathrm{S}-\mathrm{G})$ filter, which applies a moving polynomial approximation. The computational comparison was applied to low and high amplitude shocks using known excitation functions. Each sum of residuals was compared for the optimized conditions of the $4^{\text {th }} \mathrm{BW}$ and S-G filters. The results of computer simulation indicated that the S-G filters exhibited better performance for the derivatives than the $4^{\text {th }}$ BW filters. In addition, an analytical comparison using experimental vibration data also indicated that the $\mathrm{S}-\mathrm{G}$ filters exhibited better derivative characteristics than the $4^{\text {th }} \mathrm{BW}$ filters.
\end{abstract}

\section{Section: RESEARCH PAPER}

Keywords: shock; acceleration; infinite impulse response filter; Savitzky-Golay filter; derivative

Citation: Hideaki Nozato, Thomas Bruns, Henrik Volkers, Akihiro Oota , A study of Savitzky-Golay filters for derivatives in primary shock calibration, Acta IMEKO, vol. 2, no. 2, article 3, December 2013, identifier: IMEKO-ACTA-02 (2013)-02-03

Editor: Paolo Carbone, University of Perugia

Received February $6^{\text {th }}, 2013$; In final form June $30^{\text {th }}, 2013$; Published December 2013

Copyright: (C) 2013 IMEKO. This is an open-access article distributed under the terms of the Creative Commons Attribution 3.0 License, which permits unrestricted use, distribution, and reproduction in any medium, provided the original author and source are credited

Funding: This work was supported by JSPS (Japan Society for the Promotion of Science) International Program for Young Researcher Overseas Visits.

Corresponding author: Hideaki Nozato, e-mail: hideaki.nozato@aist.go.jp

\section{INTRODUCTION}

The international standardization document ISO 16063-13 [1] describes shock and complex sensitivities of accelerometers determined by shock calibration. For primary shock calibration, it is important to derive an almost undistorted acceleration waveform using laser interferometry and digital signal processing. A setup involving a homodyne laser interferometer requires a digital filtering process associated with a derivative filtering to calculate acceleration from the measured displacement. To obtain a smooth acceleration waveform, ISO 16063-13 recommends the use of a $4^{\text {th }}$-order Butterworth lowpass $\left(4^{\text {th }} \mathrm{BW}\right)$ filter followed by a difference method applied twice in sequence. The $4^{\text {th }} \mathrm{BW}$ filter works to remove highfrequency noise from the photo detector output signal and may also be used to suppress the resonant frequency of mechanical parts such as the anvil [2].

Conversely, a Savitzky-Golay (S-G) filter [3] can be applied to directly obtain a $2^{\text {nd }}$ derivative with smoothing to produce a less distorted waveform of acceleration than the $4^{\text {th }} \mathrm{BW}$ filter.
To evaluate their performance, numerical simulations were conducted for a homodyne setup using known analytical excitation functions. This paper reports the characteristics of acceleration measurements using the $S-G$ filter. For the comparison, the validation of acceleration measurements using laser interferometry is also presented.

\section{BASIC INFORMATION}

\subsection{Low amplitude shock}

Figure 1 illustrates the assumed acceleration waveforms over time and their respective frequency domain spectra for lowshock. The low-shock with a duration of $0.5 \mathrm{~ms}$ has acceleration components with several metre per second square between $5 \mathrm{kHz}$ and $15 \mathrm{kHz}$. In this case, an appropriate cutoff frequency for the $4^{\text {th }} \mathrm{BW}$ filter would be $10 \mathrm{kHz}$. Thus, consideration of the spectrum of acceleration is important in shock calibration. 

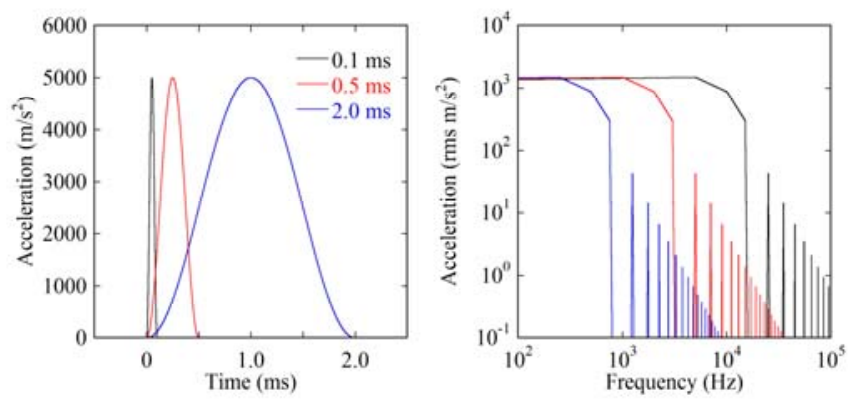

Figure 1. Computer simulations of low-shock waveforms and corresponding frequency spectra.

The low-shock is generated by a collision motion between two rigid bodies: a hammer and an anvil through a rubber pad. An accelerometer to be calibrated is attached on an edge surface of the anvil, and a low-shock motion with a shape approximating a half-sine squared function is induced to the accelerometer by the collision. Typical peak acceleration ranges from $100 \mathrm{~m} / \mathrm{s}^{2}$ to $10000 \mathrm{~m} / \mathrm{s}^{2}$ with a duration of several $\mathrm{ms}$ $[2,4]$. In the computer simulations, equation (1) was used to define the mathematical function for low-shock.

$$
a_{\text {low }}(t)=A \sin ^{2}\left[\frac{\pi}{\tau}(t-\tau)\right], \quad(\tau<\mathrm{t}<2 \tau)
$$

The value of $A$ is the peak shock acceleration. The low-shock waveform is given by the square of the sine function, and the duration is defined as $\tau$. In the range $0<t<\tau$ and $2 \tau<t<5 \tau$, the low-shock waveform vanishes.

\subsection{High amplitude shock}

The high-shock is based on elastic wave propagation inside a long thin bar and is induced to an accelerometer attached on an edge surface of the bar where a reflection of the elastic wave occurs [5]. The shape of the high-shock waveform is normally described by the $1^{\text {st }}$ derivative of the Gaussian velocity function [6]. In the computer simulations, the mathematical function for high-shock was defined by equation (2).

$$
\begin{array}{r}
a_{b i g h}(t)=A \sigma e^{0.5}\left[-\frac{(t-10 \sigma)}{\sigma^{2}}\right] e^{\left[-\frac{(t-10 \sigma)^{2}}{2 \sigma^{2}}\right]}, \\
(0<\mathrm{t}<20 \sigma)
\end{array}
$$

Figure 2 presents the assumed acceleration waveforms over time and their respective frequency domain spectra for high-
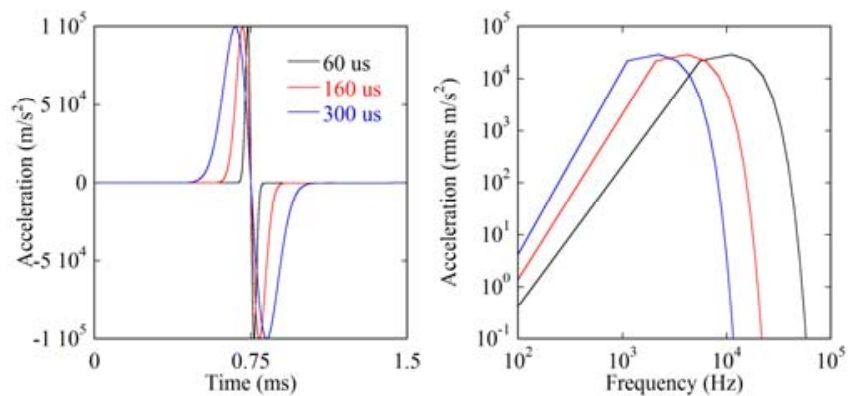

Figure 2. Computer simulations of high-shock waveforms and corresponding frequency spectra. shock. Typical peak accelerations range from $10000 \mathrm{~m} / \mathrm{s}^{2}$ to $100000 \mathrm{~m} / \mathrm{s}^{2}$ with a duration of several dozen microsecond. The shock duration is defined as $4 \sigma$. The calculation range of acceleration is set at values from $-10 \sigma$ to $10 \sigma$, such that the initial displacement becomes sufficiently small compared to the half-wavelength of the $\mathrm{Ne}-\mathrm{He}$ laser.

\section{NUMERICAL SIMULATION}

\subsection{Simulation procedure}

Figure 3 illustrates the basic procedure followed in the computer simulations. Quadrature signals with $400 \mathrm{mV}_{\mathrm{p}-\mathrm{p}}$, white noise with $10 \mathrm{mV}_{\mathrm{p}-\mathrm{p}}$, and 16-bit quantization for $\pm 16 \mathrm{~V}$ are typical specifications for the homodyne laser interferometer in NMIJ [2]. The displacement waveform is calculated by computer simulation from the original acceleration waveform. The typical quadrature signals of the $\mathrm{p}$ and $\mathrm{s}$ waves are generated in accordance with this displacement waveform [7], including the effects of white noise and 16-bit quantization. Figure 4 presents a typical waveform of acceleration, displacement, and interferometric quadrature signals obtained for a low-shock with peak acceleration of $5000 \mathrm{~m} / \mathrm{s}^{2}$ and duration of $0.5 \mathrm{~ms}$. The identification stage starts by applying the Heydemann correction [8] followed by an arctangent demodulation to obtain the reconstructed displacement waveform. Decimation is applied for reduction of data amount. Then, the acceleration waveform is reconstructed through the differentiation process using the $4^{\text {th }} \mathrm{BW}$ and $\mathrm{S}-\mathrm{G}$ filters. Thus, performance of the differentiation is investigated by computational comparison between the original and reconstructed accelerations.

\section{2. $4^{\text {th }}$ order Butterworth filter}

Figure 5 presents the calculated differences between the $4^{\text {th }}$ BW (red line) and S-G (blue line) filters in the case of lowshock with a peak acceleration of $5000 \mathrm{~m} / \mathrm{s}^{2}$ and a duration of $0.5 \mathrm{~ms}$. The black line represents an assumed acceleration waveform. From this computational result, the assumed

Low shock: $(\sin )^{2}$ with a duration of $0.1 \mathrm{~ms}$ to $2.0 \mathrm{~ms}$ High shock: dG/dt with a duration of $60 \mu$ s to $300 \mu \mathrm{s}$

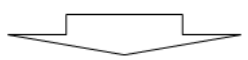

Quadrature signals with $400 \mathrm{mVp}$-p for homodyne interferometer

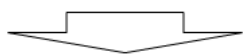

White noise with $10 \mathrm{mVp}-\mathrm{p}, 16$ bit quantization in $\pm 16 \mathrm{~V}$

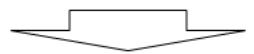

Heydemann correction, Displacement using arctan, Decimation

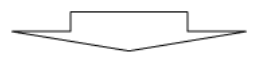

$2^{\text {nd }}$ order BW, difference, $2^{\text {nd }}$ order BW in reverse time, difference Savitzky-Golay filter (order, side points)

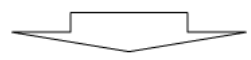

Comparison of each acceleration waveform

Figure 3. Procedure of numerical simulation. 

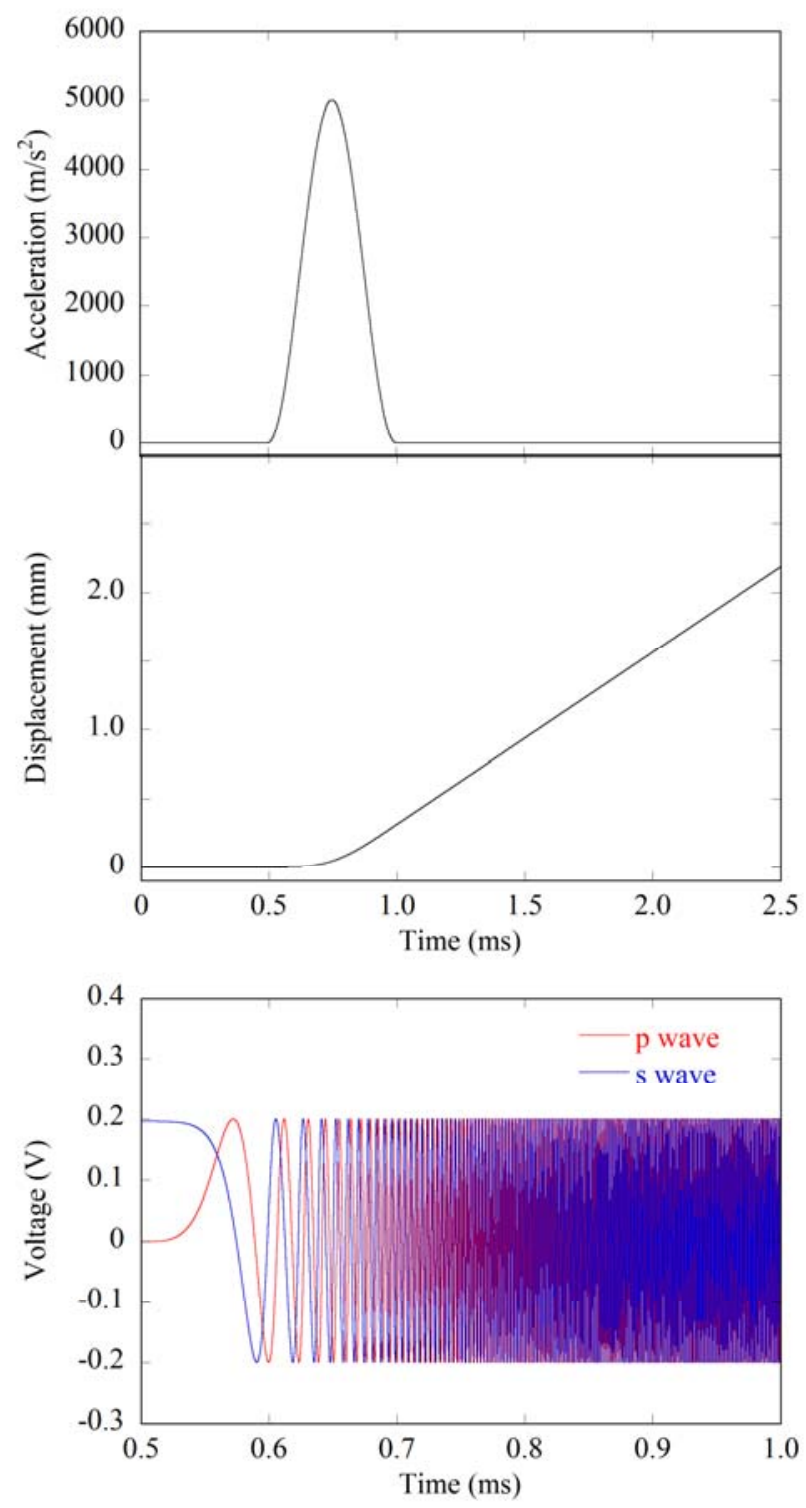

Figure 4. Example of acceleration, displacement, and interferometric quadrature signals ( $p$ and $s$ waves) in computer simulation of low-shock with peak acceleration of $5000 \mathrm{~m} / \mathrm{s}^{2}$ and duration of $0.5 \mathrm{~ms}$.

waveform is generated with a sampling frequency of $50 \mathrm{MHz}$ and the demodulated displacement is decimated to a sampling frequency of $10 \mathrm{MHz}$. The second and third panels in figure 5 are residuals and their spectrum compared with the assumed waveform, respectively. The cutoff frequency of the $4^{\text {th }} \mathrm{BW}$ filter is optimized to obtain the smallest residuals and is $10 \mathrm{kHz}$ (see figure 6).

Each minimal value depends on the duration. Shock waveforms have broad frequency bandwidth, as illustrated in figures 1 and 2; the longer the duration, the narrower is the frequency bandwidth covered by the shock waveform. The S-G filter is also optimized with 7 orders and 1400 side points (see figure 9). The second panel in figure 5 implies that the distortion of the S-G filter is smaller than that of the $4^{\text {th }}$ BW filter. In the third panel, the S-G filter exhibits smaller residuals in both frequency ranges (below $3 \mathrm{kHz}$ and beyond $10 \mathrm{kHz}$ in the spectrum) compared to those of the $4^{\text {th }}$ BW filter. Consequently, such a small deviation of waveform would be effective in obtaining more accurate results in terms of shock and complex sensitivities $[9,10]$.
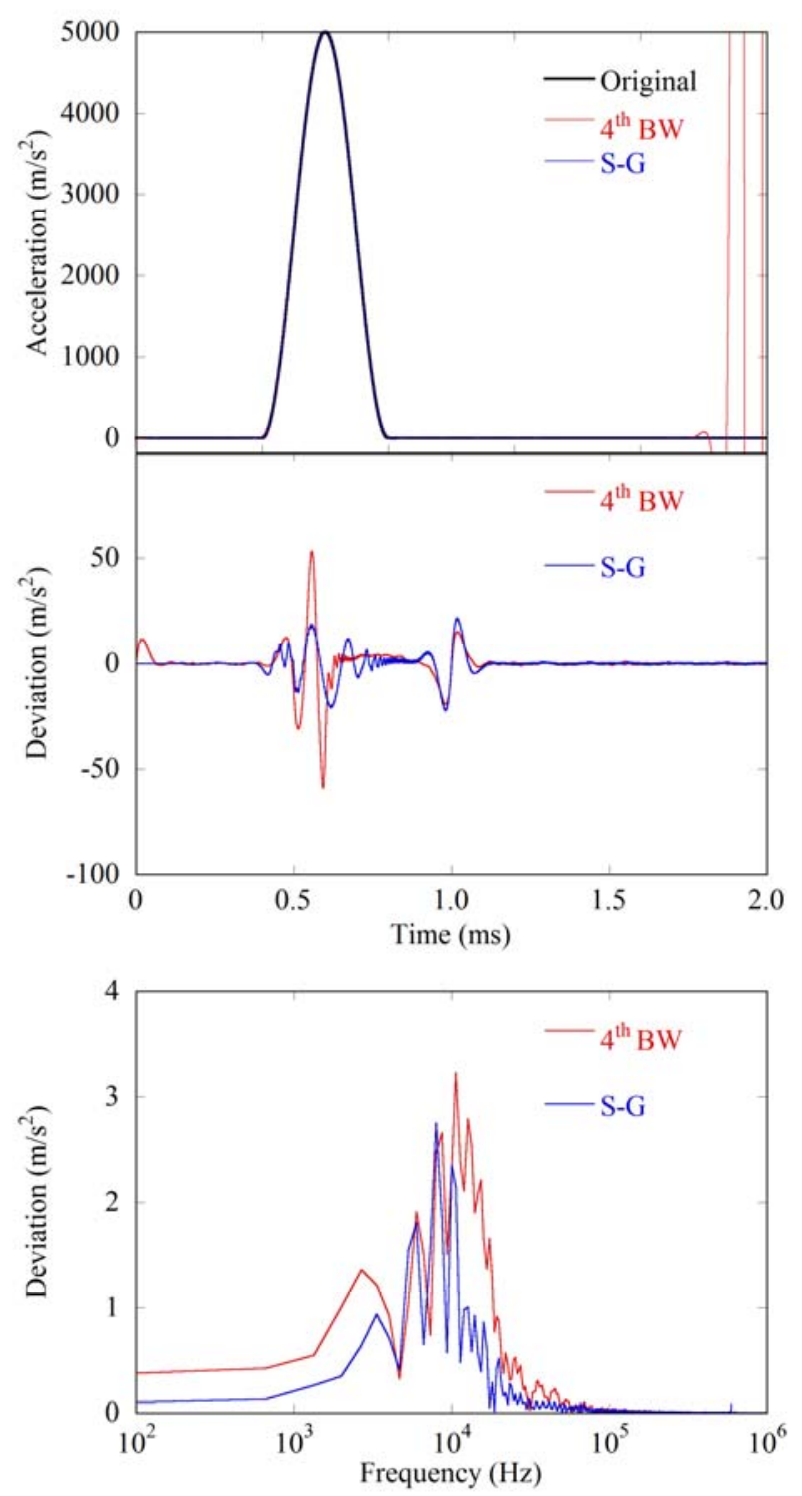

Figure 5. Assumed and two computed acceleration waveforms using the $4^{\text {th }}$ BW and S-G filters for low-shock with duration of $0.5 \mathrm{~ms}$. Deviation and spectrum between assumed and two optimized acceleration waveforms.

Figure 7 illustrates the dependence of the deviation of the assumed peak acceleration from the computed peak acceleration for the $4^{\text {th }}$ BW filter on the selected cutoff frequency. This result indicates that the peak acceleration that

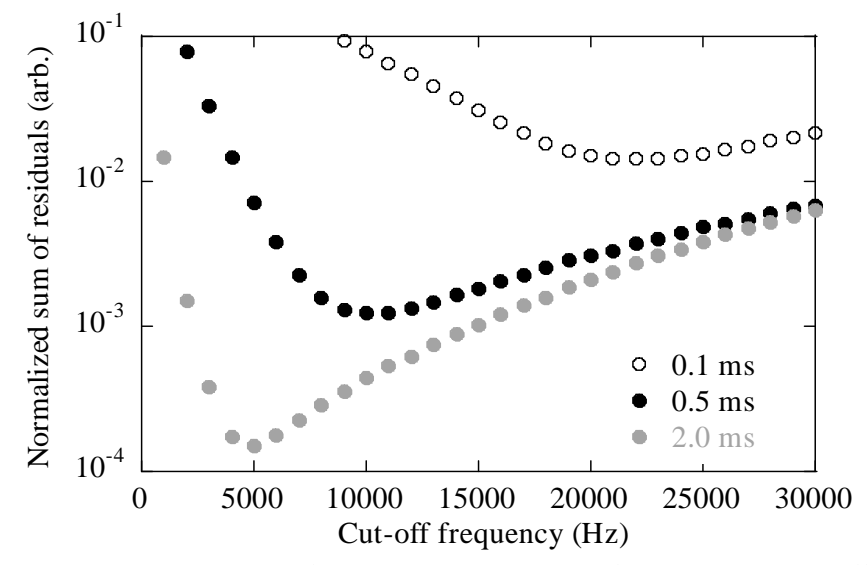

Figure 6. Dependence of the normalized sum of residuals on cutoff frequency for 3 different durations of low-shock. 
can be measured by a laser interferometer is more accurate for longer durations. For a duration of $0.5 \mathrm{~ms}$, a deviation of less than $0.1 \%$ corresponds to a cutoff frequency below $10 \mathrm{kHz}$. According to figures 6 and 7 , a cutoff frequency of $10 \mathrm{kHz}$ is suitable to obtain both a less distorted waveform and a more accurate peak acceleration, for low-shock durations of $0.5 \mathrm{~ms}$.

In order to more accurately measure the acceleration waveform using a homodyne laser interferometer, the authors recommend selecting a duration greater than $0.5 \mathrm{~ms}$. However, it should be noted that the appropriate duration and cutoff frequency depend strongly on the mechanical resonance of each shock calibration machine [2].

Figure 8 shows the computed differences between $4^{\text {th }}$ BW (red line) and S-G (blue line) filters in cases of high-shock with peak acceleration of $100 \mathrm{~km} / \mathrm{s}^{2}$ and duration of $160 \mu \mathrm{s}$. Additionally, this graph visually implies that a S-G filter with 7 orders and 440 side points can achieve smaller deviations of the acceleration waveform than can be achieved with the optimal $4^{\text {th }}$ BW filter.

\subsection{Savitzky-Golay filter}

Figure 9 illustrates the dependence of the sum of residuals on the order and number of side points of the $S-G$ filter for low-shock, peak acceleration of $5000 \mathrm{~m} / \mathrm{s}^{2}$, and duration of $0.5 \mathrm{~ms}$. The sum of residuals using the $4^{\text {th }} \mathrm{BW}$ filter is minimized by optimizing the cutoff frequency $(10 \mathrm{kHz})$ as shown in figure 6 . The sum of residuals indicates that the $S-G$ filter with 7 orders and 1400 side points is optimal under the chosen conditions.

Table 1 summarizes the optimal value of each cutoff frequency in $4^{\text {th }} \mathrm{BW}$ filters and side point in $\mathrm{S}-\mathrm{G}$ filters.

Table 1. Optimal values of cutoff frequency in $4^{\text {th }}$ BW filter and window width in S-G filter.

\begin{tabular}{|c|c|c|c|c|c|}
\hline Peak $\left[\mathrm{ms}^{2}\right]$ & $\begin{array}{c}\text { Duration } \\
\text { [ms] }\end{array}$ & $\begin{array}{c}\text { Decimation } \\
\text { [MHz] }\end{array}$ & $\begin{array}{c}\text { Cut-off } \\
\text { [Hz] }\end{array}$ & Side points & $\begin{array}{c}\text { Window } \\
\text { [ms] }\end{array}$ \\
\hline 5000 & 0.1 & 50 & 21000 & NA & \\
\hline 5000 & 0.2 & 50 & 16000 & 4500 & 0.18 \\
\hline 5000 & 0.5 & 50 & 10000 & NA & \\
\hline 5000 & 1.0 & 50 & 7000 & NA & \\
\hline 5000 & 2.0 & 50 & 5000 & NA & \\
\hline 5000 & 0.1 & 10 & 23000 & 600 & 0.12 \\
\hline 5000 & 0.2 & 10 & 16000 & 900 & 0.18 \\
\hline 5000 & 0.5 & 10 & 10000 & 1400 & 0.28 \\
\hline 5000 & 1.0 & 10 & 7000 & 2000 & 0.40 \\
\hline 5000 & 2.0 & 10 & 5000 & 2800 & 0.56 \\
\hline 5000 & 0.1 & 1 & 22000 & 60 & 0.12 \\
\hline 5000 & 0.2 & 1 & 17000 & 80 & 0.16 \\
\hline 5000 & 0.5 & 1 & 10000 & 140 & 0.28 \\
\hline 5000 & 1.0 & 1 & 6000 & 220 & 0.44 \\
\hline 5000 & 2.0 & 1 & 4000 & 320 & 0.64 \\
\hline 5000 & 0.1 & 0.5 & 24000 & 30 & 0.12 \\
\hline 5000 & 0.2 & 0.5 & 15000 & 40 & 0.16 \\
\hline 5000 & 0.5 & 0.5 & 9000 & 70 & 0.28 \\
\hline 5000 & 1.0 & 0.5 & 6000 & 100 & 0.40 \\
\hline 5000 & 2.0 & 0.5 & 4000 & 160 & 0.64 \\
\hline 1000 & 0.1 & 10 & 14000 & 800 & 0.16 \\
\hline 1000 & 0.2 & 10 & 10000 & 1300 & 0.26 \\
\hline 1000 & 0.5 & 10 & 7000 & 2100 & 0.42 \\
\hline 1000 & 1.0 & 10 & 5000 & 3000 & 0.60 \\
\hline 1000 & 2.0 & 10 & 3000 & 4300 & 0.86 \\
\hline
\end{tabular}

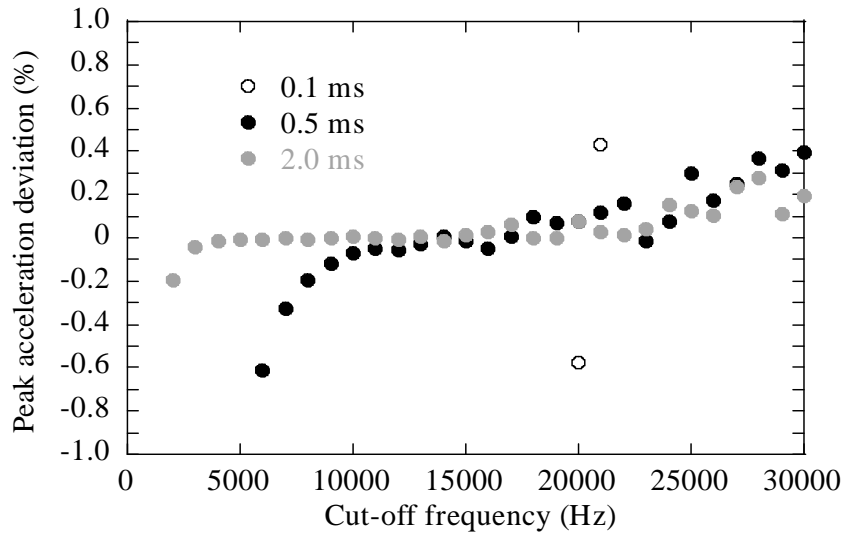

Figure 7. Dependence of peak acceleration deviation on the cutoff frequency for low-shock and 3 different durations.
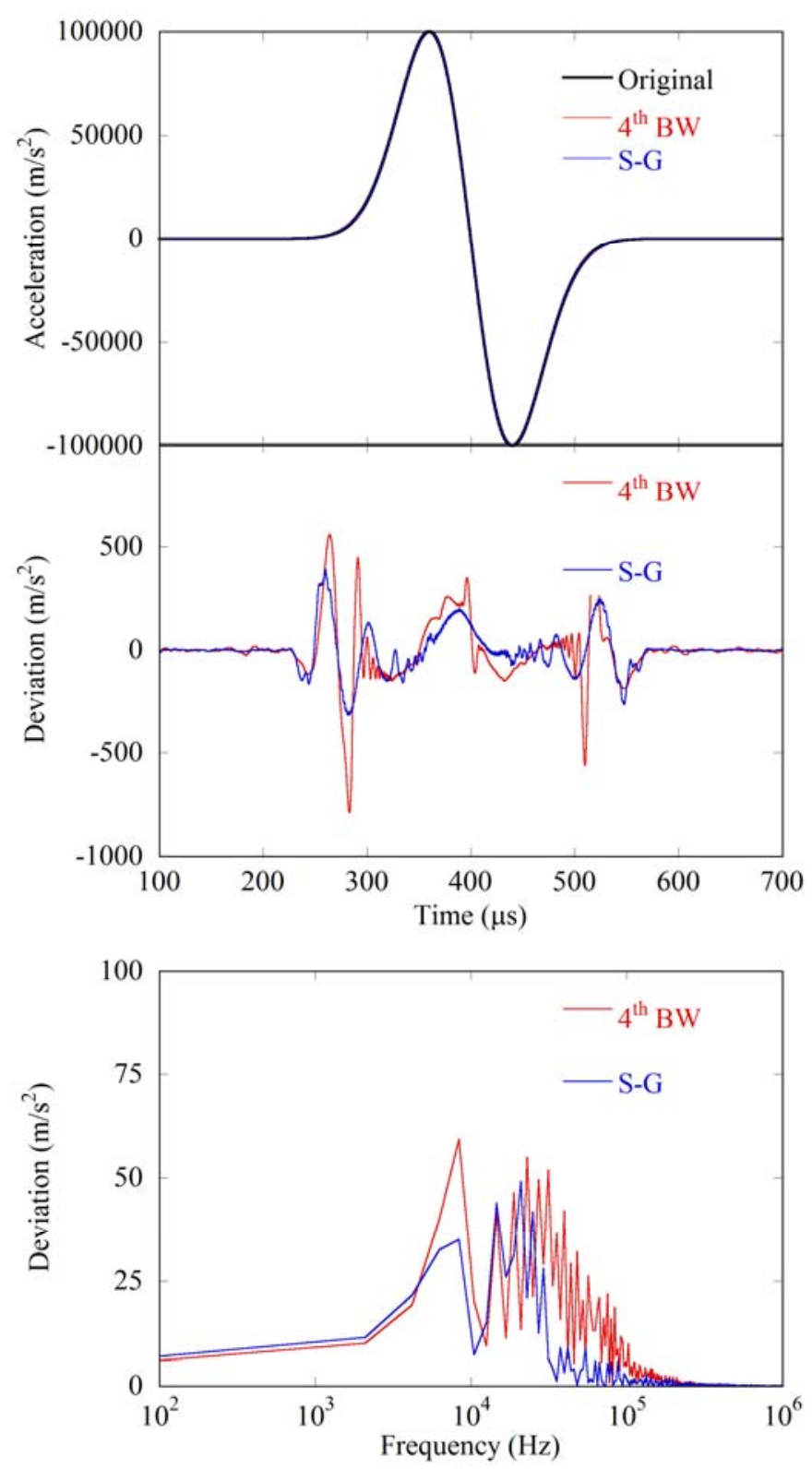

Figure 8. Assumed and two computed acceleration waveforms using the $4^{\text {th }}$ BW and S-G filters for high-shock with duration of $160 \mu \mathrm{s}$. Deviation and spectrum between assumed and two optimized acceleration waveforms. 


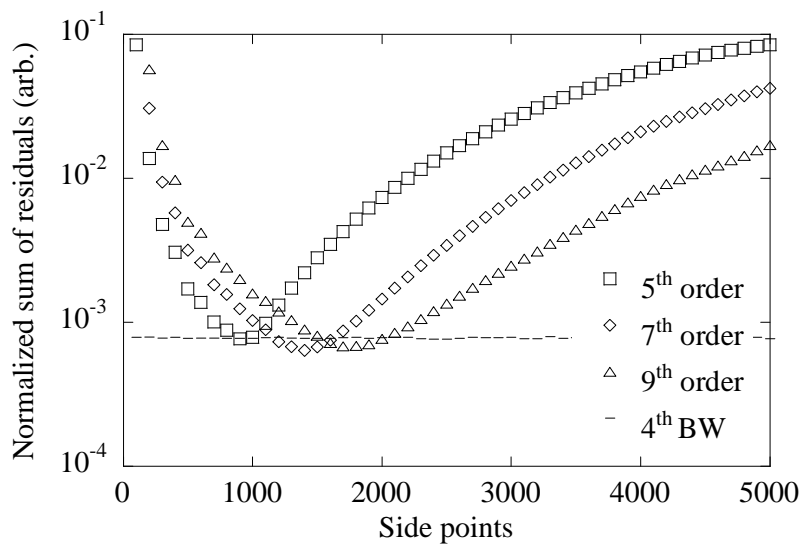

Figure 9. Sum of residuals between optimized $4^{\text {th }}$ BW filter and S-G filters of 3 different orders for low-shock and duration of $0.5 \mathrm{~ms}$.

"window" - the numerical value given by equation (3) - refers to window widths for polynomial approximation of a $\mathrm{S}-\mathrm{G}$ filter. Accordingly, peak accelerations of $1000 \mathrm{~m} / \mathrm{s}^{2}$ require lower optimal cutoff frequencies compared to those for $5000 \mathrm{~m} / \mathrm{s}^{2}$. Therefore, the effect of high-frequency noise becomes more pronounced in cases of low peak acceleration.

$$
\text { window }=[(2 \times \text { side } \text { points }+1) / \text { decimation }] \times 1000
$$

The relationship between "cut-off" and "window" for lowshock, on the basis of Table 1 , is plotted in figure 10. The closed circles represent peak acceleration of $5000 \mathrm{~m} / \mathrm{s}^{2}$ for 4 different decimations from $0.5 \mathrm{MHz}$ to $50 \mathrm{MHz}$. The open circles represent peak acceleration of $1000 \mathrm{~m} / \mathrm{s}^{2}$. These results indicate that the relationship between optimal cutoff frequency and window width is independent of three types of variables: peak acceleration, duration, and decimation.

Correspondingly, figure 11 illustrates this relationship for low and high shocks. The open circles represent high-shock, which exhibits different waveforms from low-shock. The peak accelerations are $20 \mathrm{~km} / \mathrm{s}^{2}$ and $100 \mathrm{~km} / \mathrm{s}^{2}$, and the duration ranges from $60 \mu$ s to $300 \mu \mathrm{s}$. Thus, the relationship indicates that a S-G filter works on low- and high-shocks purely as a low-pass filter (with differentiation).

\subsection{Calculation time}

The S-G filter is a kind of finite impulse response (FIR) filter in which the calculation time depends on the side points. On the other hand, since the $4^{\text {th }} \mathrm{BW}$ filter is an infinite impulse

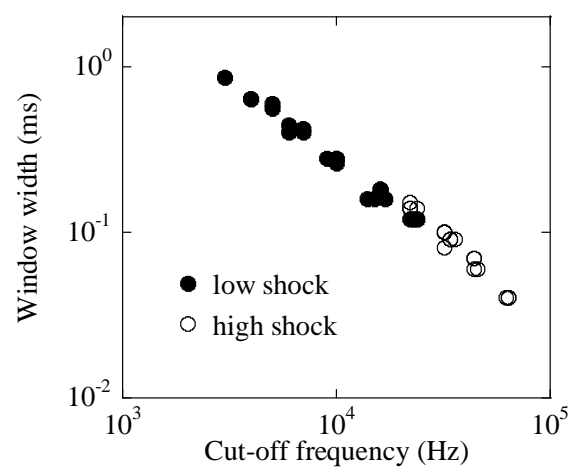

Figure 11. Relationship between optimal cutoff frequencies and window widths in low- and high-shocks.

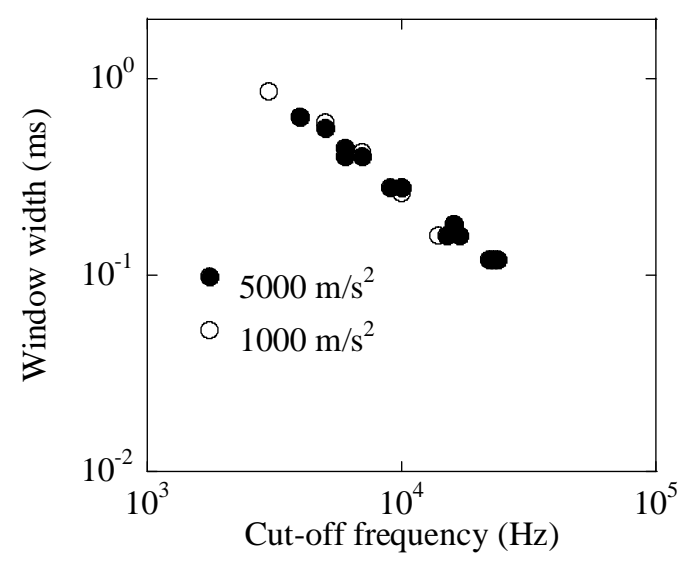

Figure 10. Relationship between optimal cutoff frequencies and window widths in low-shock.

response (IIR) filter with less filter coefficients, its calculation time is generally shorter than that of the S-G filter. So, two conditions in table 2 were selected to evaluate the calculation time between the difference method with the $4^{\text {th }} \mathrm{BW}$ filter and the $\mathrm{S}-\mathrm{G}$ filter. Here, the software and operating system were LabVIEW 2009 and Windows 7 with the central processing unit of an Intel core $i 7-2620 \mathrm{M}$ at $2.7 \mathrm{GHz}$. Then, the calculation time using the difference method with the $4^{\text {th }}$ BW filter and S-G filter was $1.029 \mathrm{~ms}$ and $123.087 \mathrm{~ms}$ in the decimation of $10 \mathrm{MHz}$. Also, that was $0.171 \mathrm{~ms}$ and $3.429 \mathrm{~ms}$ in the decimation of $0.5 \mathrm{MHz}$. Information of the calculation time was obtained using the profile performance in tools. From the results, the $\mathrm{S}-\mathrm{G}$ filter took longer time than the $4^{\text {th }} \mathrm{BW}$ filter, and each calculation time drastically decreased by the data reduction due to the decimation.

Table 2. Conditions for comparison of calculation time between difference with $4^{\text {th }}$ BW filter and S-G filter.

\begin{tabular}{cccccc}
\hline Peak $\left[\mathrm{ms}^{2}\right]$ & $\begin{array}{c}\text { Duration } \\
{[\mathrm{ms}]}\end{array}$ & $\begin{array}{c}\text { Decimation } \\
{[\mathrm{MHz}]}\end{array}$ & $\begin{array}{c}\text { Cut-off } \\
{[\mathrm{Hz}]}\end{array}$ & Side points & $\begin{array}{c}\text { Window } \\
{[\mathrm{ms}]}\end{array}$ \\
\hline 5000 & 0.5 & 10 & 10000 & 1400 & 0.28 \\
5000 & 0.5 & 0.5 & 9000 & 70 & 0.28 \\
\hline
\end{tabular}

\section{INVESTIGATION USING EXPERIMENTAL DATA}

Experimental data in shock and vibration calibrations were examined to indicate the applicability of S-G filters, even when the original waveform is unclear. Fundamentally, it is difficult to discern the correct amplitude and frequency from the shock
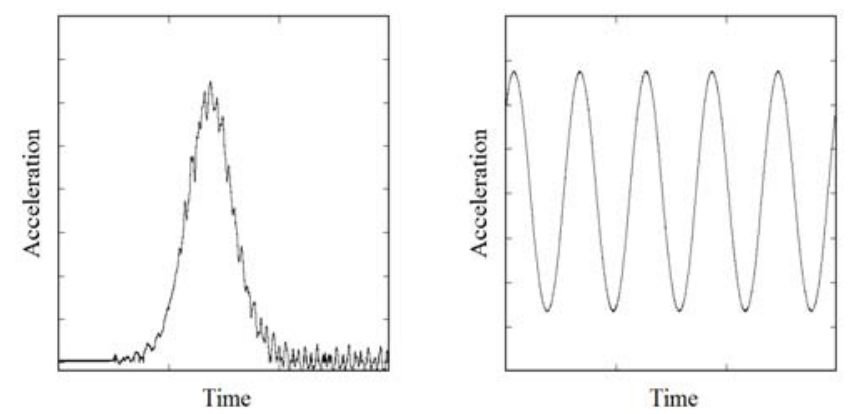

Figure 12. Typical experimental waveforms for shock and vibration calibrations. 
waveforms, as shown in figure 12. Conversely, a fundamental frequency is known in case of vibration waveforms. Therefore, in order to obtain a reference to the fundamental frequency from the vibration waveforms, a fast Fourier transform was applied to the experimental data of the NMIJ high-frequency calibration system [11].

Figure 13(a) presents an example of the displacement (black line) and its acceleration waveforms that are derived experimentally using the difference method with $4^{\text {th }} \mathrm{BW}$ (red line) and S-G (blue line) filters at the fundamental frequency of $5 \mathrm{kHz}$. Here, the two acceleration waveforms were derived from the displacement waveform. The cutoff frequency of the $4^{\text {th }} \mathrm{BW}$ filter was $10 \mathrm{kHz}$ and the side point of the S-G filter with a $7^{\text {th }}$-order polynomial was given according to the relationship illustrated in figure 11 . Thus, the displacement waveform becomes the standard against which to evaluate whether a S-G filter can differentiate more accurately than a $4^{\text {th }}$ BW filter. Figure 13(b) shows a deviation between nominal and differentiated acceleration waveforms using $4^{\text {th }}$ BW and S-G filters. Firstly, the nominal acceleration waveform $D(t)$ is derived by applying equation (4) to the displacement waveform.

$$
D(t)=b_{0}+b_{1} \sin 2 \pi f t+b_{2} \cos 2 \pi f t
$$

where $b_{0}, b_{1}$ and $b_{2}$ are parameters for sine-approximation, and $f$ is the fundamental frequency. Next, the nominal acceleration waveform is calculated by the second derivative of equation (4). As figure 13(b) shows, the S-G filter seems to have smaller deviation for the derivative than the $4^{\text {th }} \mathrm{BW}$ filter.

Figure 14 represents the spectrum of the displacement and accelerations calculated on the basis of each waveform in figure 13(a). Figure 15 illustrates the results of comparison between the $2^{\text {nd }}$ derivative of the $4^{\text {th }} \mathrm{BW}$ filter and that of the $\mathrm{S}-\mathrm{G}$ filter on the basis of this spectrum. The reference value $\alpha_{\text {Dis }}$ (black

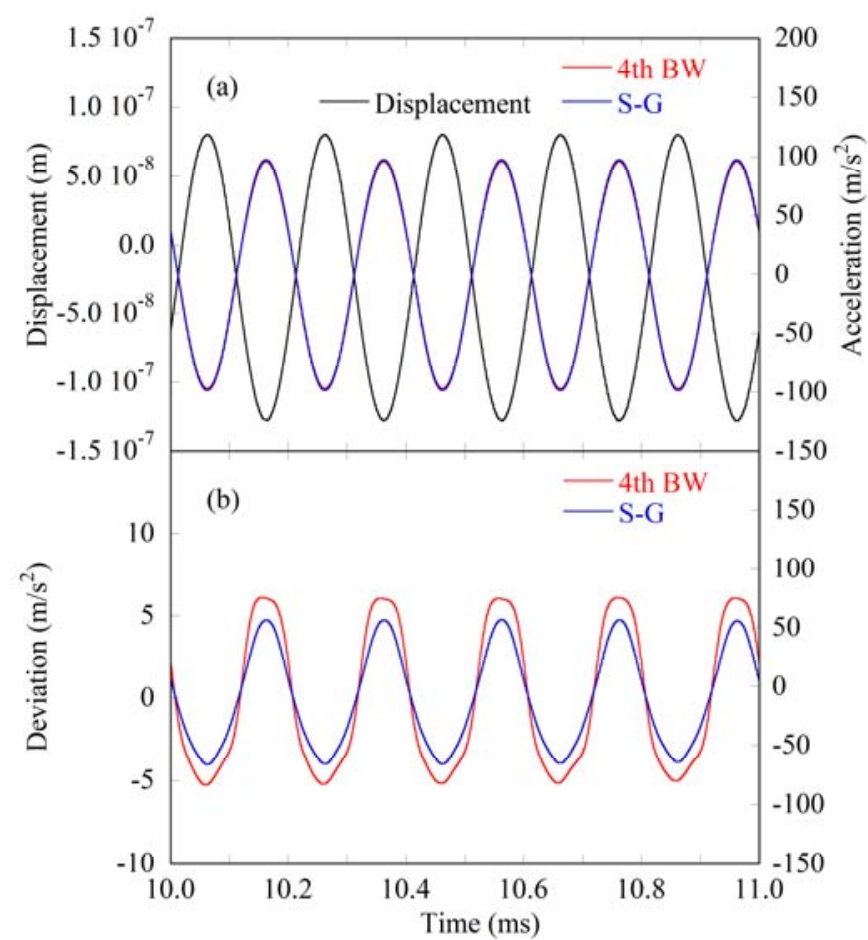

Figure 13. (a) Displacement and acceleration waveforms using $4^{\text {th }} \mathrm{BW}$ and S-G filters. (b) Deviation between nominal and differentiated acceleration waveforms using the $4^{\text {th }} \mathrm{BW}$ and S-G filters.

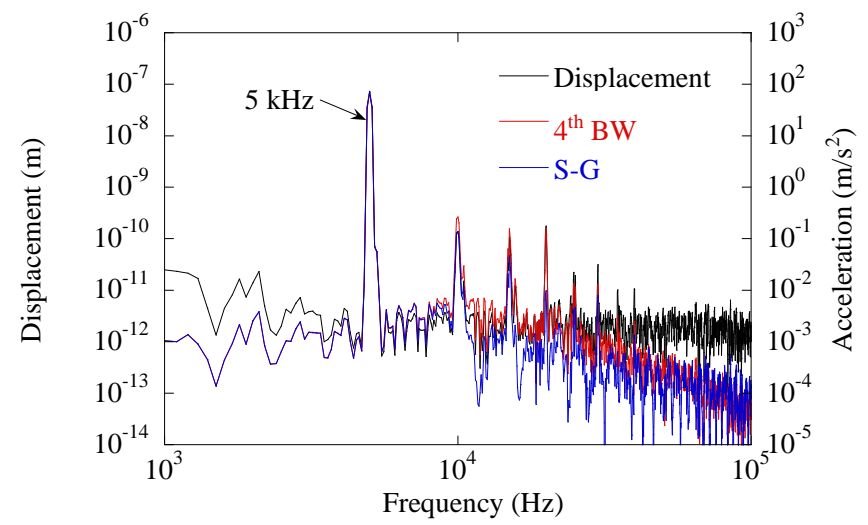

Figure 14. Spectrum of displacement and accelerations calculated using the $4^{\text {th }}$ BW and S-G filters.

circle) of the acceleration amplitude was calculated from the displacement waveform according to the following equation:

$$
\alpha_{D i s}=(2 \pi f)^{2} d
$$

The parameter $d$ is the displacement amplitude. The S-G filter is better than the $4^{\text {th }} \mathrm{BW}$ filter in two respects: the first is that the acceleration amplitude due to the $S-G$ filter is closer to the reference value than that of the $4^{\text {th }} \mathrm{BW}$ filter over the entire range of cutoff frequencies (i.e., up to $50 \mathrm{kHz}$ ); the other is that the total harmonic distortion of the S-G filter is smaller than that of the $4^{\text {th }} \mathrm{BW}$ filter. On this basis, it can be concluded that the $2^{\text {nd }}$ derivative of the $S-G$ filter performed better than that of the $4^{\text {th }}$ BW filter in obtaining the acceleration waveform for shock calibration.

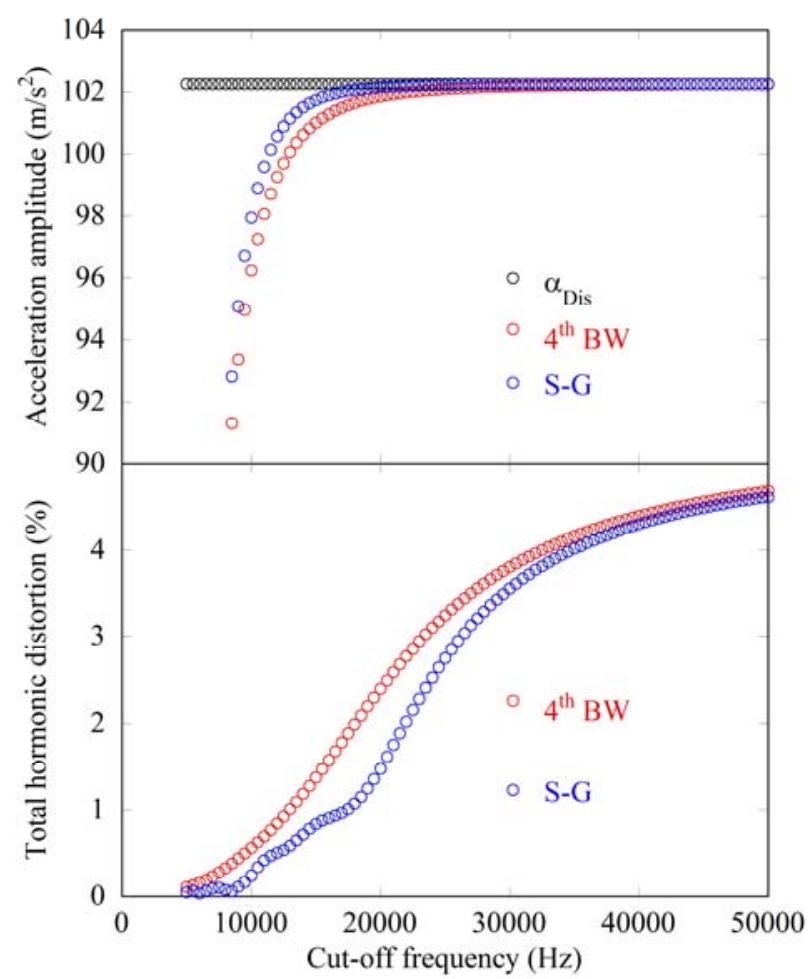

Figure 15. Comparison of acceleration amplitude and total harmonic distortion between the $4^{\text {th }}$ BW and S-G filters. 


\section{SUMMARY}

An approach for the calculation of derivatives using a S-G filter to obtain appropriate waveforms of acceleration in low and high shocks was proposed and discussed on the basis of computer simulations. The obtained waveform was compared with waveforms that were differentiated and smoothed twice using a $4^{\text {th }} \mathrm{BW}$ filter according to the procedure proposed in [1]. A relationship was derived from each optimal residual summation between $4^{\text {th }} \mathrm{BW}$ and $\mathrm{S}-\mathrm{G}$ filters with $7^{\text {th }}$ orders; this relationship did not depend on the decimation, peak acceleration, duration, or waveform in cases of low or high shocks. The results imply that the S-G filter produces better derivative and low-pass characteristics than the $4^{\text {th }} \mathrm{BW}$ filter for both low and high shocks.

An analytical comparison between the derivatives of the $4^{\text {th }}$ BW and S-G filters was investigated using experimental vibration data; fast Fourier transform was applied to the displacement and two acceleration waveforms of the $4^{\text {th }}$ BW and $S-G$ filters. This analytical comparison also indicated that the acceleration amplitudes of the S-G filter were closer to the reference values derived from the displacement than those of the $4^{\text {th }}$ BW filter. Moreover, the $\mathrm{S}-\mathrm{G}$ filter was considered superior in terms of total harmonic distortion. These results could lead to a more accurate measurement of shock and complex sensitivity for primary calibration of accelerometers implemented according to [1]

\section{ACKNOWLEDGEMENTS}

The authors would like to thank the staff of the working groups "Realization of acceleration" and "Impact Dynamics" of PTB for their helpful partnerships and constructive suggestions.

This paper was drawn up on the basis of an international collaboration between PTB and NMIJ. This work was supported by the JSPS (Japan Society for the Promotion of Science) International Program for Young Researcher Overseas Visits.

\section{REFERENCES}

[1] ISO 16063-13:2001 Methods for the calibration of vibration and shock transducers - Part 13: Primary shock calibration using laser interferometry.

[2] H. Nozato, T. Usuda, A. Oota, T. Ishigami, Calibration of vibration pick-ups with laser interferometry: part IV. Development of a shock acceleration exciter and calibration system, Measurement Science and Technology, vol. 21, no. 6 (2010), 065107.

[3] A. Savitzky, M.J.E. Golay, Smoothing and differentiation of data by simplified least squares procedures, Analytical Chemistry, vol. 36, no. 8 (1964) pp. 1627-1639.

[4] Y. Huang, J. Chen, H. Ho, C. Tu, C. Chen, The set up of primary calibration system for shock acceleration in NML, Measurement, vol. 45, no. 10 (2012) pp. 2383-2387.

[5] R.M. Devies, A critical study of the Hopkinson pressure bar, Philosophical Transactions of the Royal Society A, vol. 240, no. 821 (1948) pp. 375-457.

[6] K. Ueda, A. Umeda, H. Imai, Uncertainty evaluation of a primary shock calibration method for accelerometers, Metrologia, vol. 37 (2000) pp. 187-197.

[7] H. Nozato, T. Usuda, A. Oota, T. Ishigami, The methods for the calibration of vibration pick-ups by laser interferometry: part $\mathrm{V}$. Uncertainty evaluation on the ratio of transducer's peak output value to peak input acceleration in shock calibration, Measurement Science and Technology, vol. 22, no. 12 (2011), 125109.

[8] P.L.M. Heydemann, Determination and correction of quadrature fringe measurement errors in interferometers, Applied Optics, vol. 20, no. 19 (1981), pp.3382-3384.

[9] T. Bruns, A. Link, F. Schmähling, H. Nicklich, C. Elster, Calibration of acceleration using parameter identification Targeting a versatile new standard, proc. of XIX IMEKO World Congress, Lisbon, Portugal (2009), pp. 2485-2489.

[10] A. Link, A. Täubner, W. Wabinski, T. Bruns, C. Elster, Calibration of accelerometers: determination of amplitude and phase response upon shock excitation, Measurement Science and Technology, vol. 17, no. 7 (2006), pp. 1888-1894.

[11] A. Oota, T. Usuda, H. Nozato T. Ishigami, Development of primary calibration system for high frequency range up to 10 $\mathrm{kHz}$, proc. of IMEKO 20 $0^{\text {th }} \mathrm{TC} 3,3^{\text {rd }} \mathrm{TC} 16$ and $1^{\text {st }} \mathrm{TC} 22$ International Conference, Merida, Mexico (2007), ID-103. 